\title{
NARRATIVAS NO ESTÁGIO DE DOCÊNCIA: OUTROS OLHARES PARA A PESQUISA NA EDUCAÇÃO QUÍMICA
}

\author{
Lais Francielle Costa da Rosa ${ }^{\mathrm{i}}$ \\ Aline Machado Dorneles ${ }^{\text {ii }}$
}

\begin{abstract}
Resumo: O presente artigo apresenta o caminho inicial de uma pesquisa de mestrado em Educação em Ciências, por meio das narrativas vividas no estágio de docência da professora pesquisadora, a partir de uma perspectiva teórica e metodológica da investigação narrativa. Tem como objetivo compreender as experiências na sala de aula da formação inicial de professores de Química. Partindo das narrativas, busca o reconhecimento da experiência como um modo de fazer pesquisa com autoria, sentimentos e questionamentos visando a construção de conhecimento na formação de professores. Sendo assim, a proposta do estágio de docência desenvolveu um estudo a respeito da pesquisa/investigação na área de Educação Química, com a intenção de relacionar a imagem estética com o encontro de uma temática de investigação.
\end{abstract}

Palavras-Chave: Experiência; Investigação Narrativa; Formação Docente; Pesquisa.

\section{NARRATIVAS EN LA ETAPA DOCENTE: OTRAS MIRADAS PARA LA INVESTIGACIÓN EN EDUCACIÓN QUÍMICA}

\begin{abstract}
El presente artículo presenta el recorrido inicial de una investigación de maestríaenEducación Científica, a través de las narrativas vividas enla etapa docente del docente investigador, desde una perspectiva teórica y metodológica de lainvestigación narrativa. Tiene como objetivo comprenderlas experiencias enel aula de laformación inicial de losprofesores de Química. A partir de las narrativas, se busca elreconocimiento de la experiencia como una forma de hacerinvestigaciónconautoría, sentimientos y preguntas encaminadas a laconstruccióndelconocimientoenlaformación de los docentes. Por tanto, lapropuesta de pasantía docente desarrollóunestudio sobre investigación / investigaciónenel área de Educación Química, conlaintención de relacionar laimagen estética conelencuentro de un tema de investigación.
\end{abstract}

Palabras clave: Experiencia; Investigación Narrativa; Formación Docente; Investigación.

\section{Introdução}

Uma pesquisa que busca escutar e prestar atenção como forma de estar presente, de colocar em questão o próprio caminho percorrido e a percorrer [...]

Guedes; Ribeiro (2019)

2021 Rosa; Dorneles. Este é um artigo de acesso aberto distribuído sob os termos da Licença Creative Commons Atribuição Não Comercial-Compartilha Igual (CC BY-NC- 4.0), que permite uso, distribuição e reprodução para fins não comerciais, com a citação dos autores e da fonte original e sob a mesma licença. 
Esse texto resulta da experiência vivida no estágio de docência realizado durante o mestrado na disciplina de Educação Química VIII, do curso de Licenciatura em Química da Universidade Federal do Rio Grande (FURG). O artigo escrito em primeira pessoa, retrata minhas aprendizagens como professora, na vivência do estágio na formação inicial de professores, no mesmo curso de Licenciatura em Química, que oportunizou minha formação profissional. Por isso a importância desse narrar, de uma professora egressa do curso, que retorna para viver a experiência de ser professora e pesquisadora.

A disciplina de Educação Química VIII, escolhida para meu estágio, tem como objetivo desenvolver o estudo a respeito da pesquisa/investigação na área de Educação Química. Assim, nos primeiros encontros propus um processo investigativo de modo coletivo, em que a escrita, a leitura, a crítica, a curiosidade e a construção de argumentos foram promovidas numa perspectiva que as aprendizagens e experiências são partilhadas em todo o processo. Para isso, Sousa e Galiazzi (2019, p.108) argumentam sobre o encontro do tema: "ao articular a dimensão estética ao encontro do tema, e assim favorecer no encaminhamento das atividades a possibilidade de ampliar horizontes dos estudantes em relação ao que significa pesquisar para um professor de Química".

A investigação narrativa possibilitou esse encontro com a dimensão estética, pois a partir da fundamentação de Cunha (1997), entendo que as narrativas provocam mudanças na forma como as pessoas compreendem a si próprias e aos outros, como também recordam experiências vividas.

Desse modo, vivendo os caminhos da pesquisa, busco como objetivo no presente texto, compreender minha experiência docente como professora pesquisadora na disciplina de Educação Química VIII, a partir dos pressupostos teóricos metodológicos da investigação narrativa. Na presente escrita, desafio-me interpretar e compor sentidos das narrativas construídas em meu diário de campo, pois "um dos pontos de partida na pesquisa narrativa é a própria narrativa de experiências do pesquisador, sua autobiografia" (CLANDININ; CONNELLY, 2015, p. 106).

Ressalto a importância de compreender as experiências vividas no estágio de docência em nível superior, com foco na formação inicial de professores de Química, com a partilha dos desafios vividos na sala de aula, como pesquisadora e professora em formação, que vive pela narrativa de outras formas de produzir conhecimento. 


\section{Outros Olhares para Pesquisa em Educação Química}

Então deveríamos lançar mão de uma escrita "neutra", sem nome próprio, rosto e assinatura de quem escreveu? Uma escrita sem rosto, voz e corpo? [...] Afirmei - não sem uma pausa para reflexão - que não, que nosso texto partia e se nutria de nossas experiências, que as revelar era dar a ver os caminhos da pesquisa, as "pegadas" de nossa caminhada, os rastros singulares, os percursos e emaranhados; nossos passos e nossas trilhas, não trilhos! (GUEDES; RIBEIRO, 2019)

A ideia de trazer outros olhares dialoga com a reflexão de Guedes e Ribeiro (2019), pois ter uma formação docente em Química levou-me, em vários momentos, a repetir conceitos e definições, na tentativa de construir conhecimento de modo neutro. A decisão pelo mestrado em Educação em Ciências emerge dos encantamentos em ser professora, e assim vai desmistificando a ideia do fazer Ciência na Química, vista inicialmente somente entre vidrarias e bancadas de laboratório.

Então, outros olhares emergem para eu pensar e nutrir a pesquisa em Educação Química. Começo com a forma que decido escrever esse artigo: em primeira pessoa, para que meus próprios olhares incomodados se voltem para a pesquisa como um caminhar sem fim, pois o decorrer tem seus obstáculos e, com eles, a construção de aprendizagens e novas experiências. Na minha formação inicial o modelo de pesquisa estava atrelado a uma verdade absoluta e única, sendo refletido também no modo de ensinar Química. Porém, tive nas disciplinas relacionada à educação, a oportunidade de vivenciar a escola e suas singularidades sociais e éticas, e então começar a pensar em uma pesquisa outra, uma pesquisa que me permita outro olhar.

Talvez o desconhecido para mim possa ser conhecido para o outro. A citação traz uma crítica a Ciência:

[...] e segue uma linha sem desvios estabelecendo uma forma de produzir conhecimento. $\mathrm{Na}$ história profissional vivida até o momento, principalmente, após minha vivência no estágio de docência, compreendo que há como produzir Ciência de outros modos, abrir-me para caminhos desconhecido, com desvios inesperados, pois percebo que é nos desvios que posso produzir conhecimento, "onde o pesquisar é um processo de criação e não de mera constatação. (GUEDES; RIBEIRO, 2019, p. 33)

Desse modo, afirmo aqui a investigação narrativa como Ciência. Chaves (2000, p. 87) aponta esse processo inspirada em Benjamin (1968) ao trazer que "a narrativa é vítima de uma época que valoriza o discurso não-narrativo como uma medida de sofisticação racional, 
em oposição ao 'valor do prazer' que as histórias possuem”. Nos últimos anos a narrativa está ganhando reconhecimento e espaço nas pesquisas no campo da educação como afirma Guedes e Ribeiro:

[...] vêm se constituindo sobre esses preceitos da escuta e do diálogo, bem como outros campos que têm se desafiado a enxergar a narrativa e a experiência como nutrientes para o pensar, o indagar. $\mathrm{O}$ processo de dar sentido/significado através do narrar-se pode ser visto como emancipatório, pois consiste em uma forma de dar expressão à experiência pessoal. (GUEDES; RIBEIRO, 2019, p. 41)

Com a intenção de constituir novos olhares para pesquisa na Educação Química com preceitos da escuta, da partilha e da conversa para fomentar a experiência como caminho de investigação. Esses novos olhares e percepções sobre a pesquisa na Educação Química levamme a fazer a seguinte pergunta: o que aprendi sobre Ciência na minha formação inicial?

Pergunta que perpassa inicialmente ao conceito de uma Ciência única, mas quando questionada, permite pensar e argumentar que existem outros caminhos a percorrer para a produção de conhecimento, e que nesses caminhos devemos nos permitir, permitir um novo olhar, mais humano e relacional. Assim, adentro a narrativa como modo de pensar e como estrutura para organizar nosso conhecimento. O formato narrativo é, provavelmente, a forma mais natural e recorrente de expressar a experiência e o conhecimento (BRUNER, 2001).

A pesquisa narrativa nos permite projetar possibilidades e princípios de uma Ciência construída nas diferenças, na inclusão e na horizontalidade. A produção de conhecimento atrelada à narrativa como uma opção epistêmico-teórico-político-metodológica (RIBEIRO; SAMPAIO; SOUZA, 2016).

Nesse sentido, a pesquisa narrativa abre possibilidades de novos olhares, permitindo viver o desconhecido, o não percebido, o oculto, um conhecimento com o outro que dá importância à fala, escuta, conversa, evidenciando os sentimentos, afetos e trocas. Pesquisamos e somos parte da pesquisa, como aponta Guedes e Ribeiro (2019) sobre a travessia durante a experiência, esse movimento na pesquisa narrativa nos permite, além de pesquisar sobre e com o outro, pesquisar nós mesmos. Assim, a importância desse partilhar das experiências em grupo, como um movimento de alteridade dos sujeitos, deve ser contínua de forma atenta ao acontecer na pesquisa.

A continuidade se faz necessária pela conexão das histórias de si e do outro. Percebo no diálogo trazido até o momento, que as ideias se conectam, permitindo-me construir uma ciência a partir da experiência, com resgate de outros olhares, invisíveis ou nebulosos diante 
dos olhares mesmos de um único modo de fazer Ciência. Quem sabe aquela pesquisa desobediente ${ }^{\mathrm{iii}}$ que fuja do normal e traga esse outro lugar, olhar, sentimento, atenção, para seu mundo quanto ao conhecimento.

\section{Investigação Narrativa na Educação Química}

A área da Educação Química vem sendo bastante pesquisada pela diversidade de abordagens metodológicas em pesquisa qualitativa. As metodologias utilizadas são no viés quantitativo e/ou qualitativo, como aborda Mól (2017) ao apresentar a pesquisa em Ensino de Química e diferenciar as metodologias: no quantitativo, os dados coletados sempre são quantificados gerando medidas; e na pesquisa qualitativa, foco do presente texto, o interesse é compreender como que o sujeito vivencia o fenômeno e descreve o mesmo. Mól (2017) aponta para os tipos de abordagens comuns em trabalhos de pesquisa na área de Ensino de Ciências na pesquisa qualitativa, sendo essas: pesquisa narrativa, pesquisa etnográfica, investigação-ação, pesquisa estudo de caso, pesquisa fenomenológica e pesquisa documental.

Proponho a investigação narrativa como um estudo da experiência vivida pelo sujeito, com a intenção de compreender como é vivida determinada experiência (CLANDINNIN; CONNELLY, 2015). Diante disso, a pesquisa narrativa vem adentrando na área da Educação Química, na maioria das pesquisas centrada na escrita associada à formação de professores. Como traz Dorneles e Galiazzi (2016) a respeito da investigação narrativa relacionada às atividades experimentais na Química:

[...] a imersão na pesquisa narrativa possibilitou compreender a experimentação investigativa como evento na formação de professores de Química, a partir das narrativas da experimentação (histórias vividas no evento) como também as narrativas da experiência de cada um a vivenciar o evento. (p. 189)

Desse modo, me permito compreender minha experiência vivida no estágio de docência realizado na disciplina de Educação Química VIII, do sétimo semestre do curso de Licenciatura em Química da FURG. A disciplina teve como temática a pesquisa na área da Educação Química, sendo assim o desafio foi oportunizar o vivenciar da pesquisa com a articulação da dimensão estética ao encontro do tema. Foi proposto o encontro com uma imagem estética e as narrativas autorais na experiência da disciplina, inclusive a minha como pesquisadora/participante.

Revista Interinstitucional Artes de Educar. Rio de Janeiro, V. 7, N. 1 - pág. 410-426 janeiroabril de 2021: "Pedagogias Vitais: Corpo, Desejo e Educação" DOI: 10.12957/riae.2021.54917 
Esse movimento da disciplina/pesquisa proporcionou escritas de narrativas com sentimentos, emoções, vivências, lembranças, aprendizagens etc. "Nossos interesses de pesquisa provêm de nossas próprias histórias e dão forma ao nosso enredo de investigação narrativa" (CLANDININ; CONNELLY, 2015, p.165). Após a escolha da imagem estética, proposta pela disciplina, três (3) narrativas foram construídas de modo a pensar e se atentar a cada movimento dado na disciplina. Aqui, apresento um breve roteiro das narrativas construídas a cada movimento proposto na disciplina: primeira narrativa apresentando a imagem escolhida, segunda narrativa respondendo à pergunta: "qual o motivo de escolher essa imagem?", e a terceira, uma escrita livre de forma a interpretar e compreender os caminhos percorridos na disciplina para o encontro com tema de investigação.

Sendo assim, escrevi minhas narrativas a partir das vivências durante o caminhar da disciplina, pelos desafios vividos na sala de aula e, também, pela forma outra de conduzir a disciplina. O caminho da experiência vivida se deu com o propósito da escrita, pois o objetivo da disciplina compreende a potência da escrita na formação inicial dos professores, juntamente com Calixto e Galiazzi:

A escrita, nesse contexto, potencializa as compreensões construídas ao longo do percurso de ser professor/ pesquisador, explicitando ao escrevente o que precisa ser desenvolvido e o que é compreendido. A compreensão da escrita enquanto meio de formação foi se consolidando à medida que se percebiam transformados pela mesma. Primeiramente, rompendo as barreiras com o escrever, por meio do exercício contínuo de se desafiar a expor argumentos e, posteriormente, compreendendo a potencialidade recursiva da escrita. (CALIXTO; GALIAZZI, 2017a, p. 177-178)

Com esse entendimento quanto à potencialidade da escrita, escrevi narrativas de cada aula vivida no estágio de docência. Em meu diário, narrei os caminhos da disciplina percorridos por mim, um narrar livre sobre minhas vivências nessa experiência. Posteriormente, a interpretação das minhas narrativas buscou perceber como vivenciei a experiência da docência no decorrer da disciplina, a partir dos estudos de Cladinin e Connely (2015), que relacionam a investigação narrativa como um caminho para entendimento da experiência. Para os autores:

[...] experiências são as histórias que as pessoas vivem. As pessoas vivem histórias e no contar dessas histórias se reafirmam. Modificam-se e criam novas histórias. As histórias vividas e contadas educam a nós mesmo e aos outros, incluindo os jovens e os recém pesquisadores em suas comunidades. (CLANDININ; CONNELLY, 2015, p. 27) 


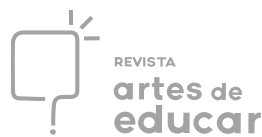

Assim, a perspectiva teórica metodológica da investigação narrativa favoreceu a composição de sentidos da minha experiência vivida no estágio de docência. Compreendo a composição de sentidos por Clandinin e Connelly (2015) como sendo um modo de interpretar o narrado. Nesse sentido, a interpretação da experiência se dá de forma individual e singular com reencontro da minha própria narrativa interpelada pelos acontecimentos vividos em cada aula planejada e desenvolvida. Os sentidos/significados são composições da pesquisadora, desse modo cada um encontra o caminho de apresentar suas interpretações narrativas. É um constante vivenciar a experiência em que o entendimento e a composição de sentido se limitam pela vivência do sujeito em seu narrar (CLANDININ E CONNELLY, 2015).

Quando pesquisadores narrativos estão em campo, eles nunca estão ali como mentes (sem corpo) registradoras da experiência de alguém. [...] A experiência da narrativa do pesquisador é sempre dual, é sempre o pesquisador vivenciando a experiência e também sendo parte da própria experiência. (CLANDININ; CONNELLY, 2015, p. 120)

Nesse movimento de pesquisa percebo-me como pesquisadora em formação ao investigar minha própria experiência do estágio de docência. Desse modo, sem ter seguido uma metodologia nos formatos acadêmicos, apresento os sentidos construídos ao promover o encontro com a dimensão estética na busca de desenvolver o estudo a respeito da pesquisa na Educação Química.

\section{As Experiências na Disciplina como Professora Pesquisadora}

A disciplina de Educação Química VIII, no primeiro semestre de 2019, foi composta por seis estudantes, a professora pesquisadora e a professora orientadora do estágio. Com objetivo de desenvolver o estudo a respeito da pesquisa/investigação na área de Educação Química, oportunizando o vivenciar da pesquisa com a articulação da dimensão estética ao encontro do tema. Assim, minha primeira narrativa resgata o começo do estágio, o viver da docência na formação de professores:

Primeiro dia de aula de estágio, e o frio na barriga... fica difícil de controlar. A aula planejada e organizada com a professora orientadora centrou na abordagem dos tipos de pesquisa qualitativa mais utilizados no ensino de Química, embasado em artigos da área, com busca no Google acadêmico e na QNEsc (Revista Química Nova na Escola). Criamos 


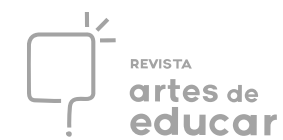

um espaço online, uma pasta no Google drive, para que os alunos tivessem disponíveis os artigos apresentados em sala de aula. Durante a aula para cada abordagem de pesquisa utilizada mostramos exemplos de metodologias nos artigos. Ao final da aula, que por sinal foi bem interessante, uma aluna falou que precisava de ajuda para encontrar um tema de seu interesse para pesquisar. Minha expressão foi de espanto e ao mesmo tempo de felicidade, pois o rumo dos estudos seguia ao encontro com o objetivo de pesquisa do meu mestrado. Seria um desafio lançado esse pedido de ajuda da estudante? Acabando a aula e com aquele pedido na "cabeça", conversando com minha orientadora, foi sugerida uma leitura do artigo de Simplício e Galiazzi (2019) que seguia a linha do encontro com o tema de pesquisa, transformando o tema em questão a pesquisar. A partir desse momento percebi que os estudos e leituras seriam aprofundados para que a próxima aula pudesse ser novamente um envolvimento com a proposta de fazer pesquisa na área da Educação Química.

Em um movimento de (re)ler a narrativa da organização da aula, começo a compor sentido nesse primeiro encontro. Meu olhar se volta na inquietação da colega, que quando contou a história me fez relembrar que, em algum momento, passei pelo mesmo sentimento de dificuldade em encontrar o tema de pesquisa, que, no meu caso, era para o TCC. Cladinin e Connelly (2015, p. 107) apontam para esse movimento de recordar histórias passadas ao escutar, ou escrever, ou contar, uma narrativa, como um espaço tridimensional: "ao compormos nossas narrativas, nos movemos no espaço tridimensional, relembramos histórias passadas que influenciam nossas perspectivas presentes através de um movimento flexível [...]". E nessa recordação lembro-me da importância de o tema ter relação com o sujeito, e nessa disciplina buscamos esse encontro.

Com a leitura do artigo de Sousa e Galiazzi (2019), percebo a importância e intenção de desencadear um primeiro movimento ao encontro de um tema a se pesquisar a partir de experiências que normalmente são desconsideradas quando se estuda Química. A Química está muito relacionada a conteúdo e pouco ao campo de pesquisa. Moraes (2002, p. 231) aponta que "a construção do objeto de pesquisa é um exercício de compreensão do pesquisador de si próprio, um movimento de dentro para fora". Seguindo a ideia de que nas experiências humanas há um campo de investigação, pelas experiências vividas, fundamentada por Clandinin e Connelly (2015), trago minha segunda narrativa sobre o próximo passo que a disciplina teve: 
Estava ansiosa para a aula de hoje, pois o estudo feito por mim foi bem interessante $e$ de grande aprendizagem. O nome da aula de hoje é "O encontro com o tema de pesquisa", com a aposta na experiência humana como um grande potencial formativo do sujeito. Ao apresentar a experiência estética como "ferramenta" de ajuda para o encontro de uma temática de pesquisa, percebi que já havia pensamentos dos alunos para encontrarem sua imagem estética a partir de experiências pessoais. Mostramos um espaço criado, uma pasta, no aplicativo Pinterest, com o nome da disciplina, para que ali cada estudante postasse sua imagem. Seguindo a aula, solicitamos que cada aluno encontrasse uma imagem a partir de uma experiência que viveu e que escrevesse uma narrativa respondendo o porquê da escolha daquela imagem. Finalizando a aula fiquei bem angustiada sobre como será o rumo dessa disciplina. A curiosidade tomou conta de mim de que imagens viriam representando cada aluno.

O que chama atenção nessa narrativa é o encontro com a imagem estética, esse movimento na disciplina tinha intenção de emergir uma reflexão quanto à busca, e o motivo de sua escolha. O Pinterest é uma rede social de compartilhamento de fotos. Assemelha-se a um quadro de inspirações, em que os usuários podem compartilhar e gerenciar imagens temáticas, como de jogos, hobbies, roupas, perfumes etc. Afirma Clandinin e Connelly (2015, p. 165) que "nossos interesses de pesquisa provêm de nossas próprias histórias e dão forma ao nosso enredo de investigação". Por isso a intenção da atividade, proposta na disciplina, foi fazer emergir experiências normalmente desconsideradas pelos sujeitos, como apontam Sousa e Galiazzi (2019, p. 112) "a estrutura da vivência tem estreita afinidade com a estética, isto fica mais evidente, especialmente, se nos atentarmos para o modo de como é interpretado uma obra de arte". Fundamentando o modo de interpretar uma obra de arte, nesse mesmo artigo, Sousa e Galiazzi relacionam Gadamer como um filósofo que se dedicou ao fenômeno da compreensão, "[...] da experiência interpretativa com a arte para fundamentar que, a interpretação é busca de compreensão dentro da qual não conseguimos suspender nossos preconceitos, nossa historicidade e nossas vivências". (GADAMER, 2015, apud SOUSA e GALIAZZI, 2019, p. 112)

Por acreditar que nas experiências humanas há um campo investigativo que parte das histórias de cada sujeito, a disciplina proporciona esse encontro do estético com a experiência. Nos primeiros encontros da disciplina foi criada uma pasta na conta Pinterest, para que a imagem estética que remetia alguma experiência vivida e que tinha alguma intenção fosse postada. Como afirma Salomon (2010) que a "experiência pessoal" serve de/para inspiração e Revista Interinstitucional Artes de Educar. Rio de Janeiro, V. 7, N. 1 - pág. 410-426 janeiroabril de 2021: "Pedagogias Vitais: Corpo, Desejo e Educação" DOI: 10.12957/riae.2021.54917 
escolha do tema de pesquisa, a partir dessa fundamentação teórica seguimos caminhando com a disciplina em encontrar um tema a pesquisar/investigar. Minha terceira narrativa é sobre a continuidade da disciplina:

Nesse dia de aula nossa ideia foi de cada estudante apresentar sua imagem respondendo a pergunta: o que te moveu a escolher essa imagem? Tinham como tarefa a escolha da imagem e a escrita narrativa sobre a escolha. Foi um movimento bem interessante, pois aqueles que ainda não tinham narrado sua escolha se sentiram à vontade em narrar pessoalmente para todos da turma, uma aula super aberta em que todos se apresentaram a partir da imagem. Seguindo nossa proposta, planejamento de aula, foi sugerida uma rodada de perguntas sobre a imagem do outro, para que uma nova narrativa fosse escrita, talvez esse movimento de perguntas ajudasse a lembrar vivências sobre a imagem. A ideia de formação de professores/pesquisadores em foco no diálogo coletivo em rodas de formação, e na escrita em diários, fundamentada nos pressupostos teóricos, fortalece a ideia do coletivo, da escrita de perguntas, indagações sobre a imagem do outro.

Por acreditar no potencial desse movimento de pesquisa, apostando que ele constrói e compõe significados para as histórias vividas, foi solicitada uma escrita sobre essa busca pela imagem estética. Uma narrativa que permite voz e autoria, e nos desafia abrindo possibilidades de novos olhares e atenção. Sobre a construção de conhecimento coletiva aqui, nesse momento, se fez presente, ao perceber que o movimento da escrita no espaço criado não poderia ser aceito por todos. A composição de sentidos dessa narrativa se dá na interpretação e compreensão da formação de professores a partir de escrita e do coletivo. De acordo com Cunha (1997) a escrita de narrativas das experiências vividas serve como procedimento de pesquisa e como instrumento de formação, isso se dá no desenvolver das vivências da pesquisadora no estágio docência.

A escrita, nesse contexto, potencializa as compreensões construídas ao longo do percurso de ser professor/ pesquisador, explicitando ao escrevente o que precisa ser desenvolvido e o que é compreendido. A compreensão da escrita enquanto meio de formação foi se consolidando à medida que se percebiam transformados pela mesma. (CALIXTO; GALIAZZI, 2017a, p. 177-178)

$\mathrm{Na}$ escrita "o sujeito tem a liberdade de contar/recontar e reviver uma experiência de forma mais aprofundada e mais atenta" (MELLO, 2005, p. 81) o qual possibilita a reflexão, a autoria e o pensar a pesquisa a partir de si, a partir de uma experiência vivida pelo sujeito, 
sendo uma escrita em folha, ou virtual. Calixto e Galiazzi (2017) afirmam que, através da pesquisa com os professores/pesquisadores em formação, compreendem a escrita como um meio de formação, que constitui o escrevente no movimento da escrita. A partir da conversa sobre as imagens, da escrita de perguntas no coletivo, o processo formativo foi oportunizado em roda de formação, pela ideia que Souza (2011) aponta quando diz que a interpretação do sujeito pode ser diferente do que o autor imagina e colocar esse diálogo em roda favorece esse processo. A experiência em roda favoreceu um movimento de reescrita da narrativa, uma escrita com mais clareza em relação à imagem e às perguntas construídas no coletivo para cada imagem estética. Pela experiência se constrói o conhecimento, afirma Guedes e Ribeiro (2019, p. 38):

Contar histórias é uma possibilidade de dar-se a ler e de ouvir e ser ouvido. Contar histórias é deixar soar uma voz comumente reprimida na nossa escola, seja de nível básico ou superior: a voz do sujeito praticante, aquele que vive o cotidiano da escola, que o produz na tessitura com os outros. Escutar e afirmar as vozes pulsantes nas nossas experiências e saberes é, portanto, agir no sentido de valorizar nossas trajetórias, compreender nossos percursos.

Por tanto, esse movimento possibilita o reconhecimento da experiência e o quanto ela produz conhecimento. Assim, busco na narrativa documentar a experiência vivida nos momentos do caminhar da pesquisa e mostrar outras formas de conhecimento, partindo das histórias. Como Cunha (1997) traz em seu artigo, que quando uma pessoa relata os fatos vividos por ela mesma, percebe-se que reconstrói a trajetória percorrida dando-lhe novos significados. O olhar do coletivo pode ser, e é transformador da realidade do sujeito.

Nessa aula, o frio na barriga foi mais intenso ao saber que às 9 h a professora tutora sairia, e o seguimento da aula seria dado apenas por mim. Estava nervosa. Mas segui o planejamento da aula, que sempre foi feito com estudo e encontros com a professora orientadora. Segui a aula com a leitura das narrativas dos alunos, após a reescrita mediada pelas perguntas do grupo. A cada narrativa lida, percebia as histórias de vida. Experiências pessoais e reveladoras foram narradas nesse dia, que emergiram ao escolher uma imagem e criar significados para essa escolha. Essa aula foi muito bonita e inovadora, pois nela pudemos perceber o quanto as vivências nos afetam de algum modo. Em conversa, eu e a orientadora, pensamos como seria o próximo passo a ser dado na disciplina. A ideia foi seguir uma linha de como a partir da narrativa encontrar o objeto, fenômeno, a ser pesquisado.

Revista Interinstitucional Artes de Educar. Rio de Janeiro, V. 7, N. 1 - pág. 410-426 janeiroabril de 2021: "Pedagogias Vitais: Corpo, Desejo e Educação" DOI: 10.12957/riae.2021.54917 
A experiência no estágio docente possibilitou outros modos e olhares na forma de pesquisar permitindo momentos de escuta, de conversa, de troca, onde, em cada narrativa lida, havia uma abertura do coletivo, que se permitia um exercício de compreender a formação docente em sua horizontalidade em que todos aprendem juntos. A leitura de uma narrativa para o coletivo, a abertura para pergunta, inquietações, dúvidas, fazem que novos caminhos sejam traçados. Isso significa a composição de sentidos, em que a cada interpretação vem e se escreve uma nova narrativa. Nesse movimento sem perceber se compõe sentido na narrativa pela sua experiência, que a cada retorno se tem uma nova interpretação. Para Moraes (2002, p. 237) "independente da forma como se atinge o objeto de pesquisa, entende-se que estes devem ser importantes".

Assim, entendo que a aprendizagem de fazer pesquisa, principalmente, o encontro com o tema de investigação, quando compreendido pela estética, é possível construir significado para o pesquisador que se envolve a partir de suas histórias, experiências vividas. A construção da pesquisa nessa dimensão se dá de dentro para fora, a partir das vivências do pesquisador e participantes.

\section{Compreendendo a Experiência Vivida: Olhar da Pesquisadora}

Esse movimento de trazer a imagem estética teve a intenção de emergir experiências dos "sujeitos" normalmente desconsideradas quando se busca um tema de pesquisa/investigação no ensino de Química. Busco, através da imagem, compreender como a experiência foi vivida. Com essa atividade é possível refletir sobre as experiências, sobre como é possível interpretar esse movimento de experienciar o ato de fazer pesquisa. O intuito da disciplina é desencadear um primeiro movimento em direção ao encontro com o tema de pesquisa que se mostra vinculado a suas vivências, por meio do encontro e partilha das imagens estéticas.

Como pesquisadores-narrativos, partilhamos nossas escritas a partir de experiências vividas, e nessa pesquisa a experiência foi buscar a imagem estética relacionada com o pessoal, com suas histórias. Aqui não são apenas histórias recontadas por um pesquisadornarrativo, são histórias que são abertas para o pesquisar e o recontar a partir deles próprios (CLANDININ; CONNELLY, 2015). Fundamentado em Dewey (2011, p. 149), “experiência 
é tudo o que acontece a um indivíduo. Na verdade, os indivíduos se tornam conscientes de uma experiência depois da experiência".

A ideia de construção e reconstrução da experiência, para o autor e para nós pesquisadores, nunca tem um ponto final, pois esse movimento de (re)ler as narrativas, histórias vividas, faz com que novas lembranças e novas narrativas sejam escritas. Sem fim, a cada leitura de um novo sujeito, e muitas vezes o mesmo sujeito, dependendo da temporalidade, tudo pode ser modificado. E nisso se faz a composição de sentidos, interpretando a narrativa na visão do pesquisador e/ou sujeito pesquisado. Por tanto, Cunha (1997) afirma que a narrativa provoca mudanças na forma como as pessoas compreendem a si próprias e aos outros, como já citado acima. "Tomando distância do momento de sua produção, é possível, ao ouvir a si mesmo ou ao ler seu escrito, que o produtor da narrativa seja capaz, inclusive, de ir teorizando a própria experiência" (CUNHA, 1997, p. 3).

Uma das coisas que o pesquisador-narrativo faz no campo de pesquisa é estabelecer um vínculo, viver ao lado dos participantes e experimentar as histórias ao serem contadas, moldando assim a estrutura das narrativas das suas observações, e tornando suas narrativas mais verdadeiras por vivenciar a experiência com o conjunto. $\mathrm{O}$ envolvimento do pesquisador com a pesquisa é de grande importância para a formação interpretativa das experiências. E essa pesquisa acontece dessa forma, eu como pesquisadora e participante de todo o caminhar da disciplina e pesquisa. Nesse momento a narrativa que trago é uma narrativa escrita de forma livre, em que eu vivo aquele momento no estágio docência.

Primeira aula que fico sozinha com os alunos... me senti segura pelo envolvimento que já vinha adquirindo e tendo com eles. Nessa aula foi o momento em que eu conversei com os alunos da possibilidade de toda experiência vivida por mim e com eles na disciplina de ser minha pesquisa de mestrado, como resposta todos foram bem legais e aceitaram tranquilos participar como sujeitos da pesquisa. Isso tudo pelo envolvimento meu como pesquisadora com eles, que vivi toda experiência junto deles no decorrer da disciplina mostrando que não existe um distanciamento entre pesquisador e sujeitos de pesquisa. Todos somos os sujeitos a serem pesquisados. Nessa aula, me senti super bem, e vi que ali tinha minha pesquisa, pelas minhas vivências e experiências adquiridas durante esse semestre. Continuando nossa aula, nesse dia já estávamos todos com o "objeto" de pesquisa bem determinado e como seguiríamos em frente seria nosso andar das próximas aulas. Pensamos e conversamos sobre o que é corpus de pesquisa, campo de pesquisa, e que a partir de agora todos iriam experienciar um movimento inicial de fazer pesquisa. Ao final da aula, foi solicitado que Revista Interinstitucional Artes de Educar. Rio de Janeiro, V. 7, N. 1 - pág. 410-426 janeiroabril de 2021: "Pedagogias Vitais: Corpo, Desejo e Educação" DOI: 10.12957/riae.2021.54917 
cada aluno escrevesse sobre esse movimento de escolha do campo e como foi feito o caminho de pesquisa.

Essa narrativa vem, nesse momento, para mostrar a construção dessa relação entre pesquisadora e estudantes, no caminhar da pesquisa. A interpretação dessa narrativa vai ao encontro de "a construção da intimidade entre pesquisador e participante", mencionado no livro de Clandinin e Connelly (2015). Essa relação foi construída no decorrer da pesquisa (disciplina), em que cada lado se sentia à vontade em seguir junto. Evidencia-se, no entanto, que essa mesma intimidade criada na pesquisa com as vivências e experiências compartilhadas, é super frágil, pois a relação pesquisador-participante está sempre em negociação e aberta a ser modificada. Essa fragilidade está nas mudanças durante o caminhar, que são percebidas quando se busca compreender a experiência vivida. Desse ponto de vista, "a pesquisa narrativa é uma tentativa de fazer sentido da vida como é vivida" (CLANDININ; CONNELLY, 2015, p. 116).

Ao escrevermos nossas narrativas nos movimentamos no espaço-tempo, pois revivemos ao escrever uma história já vivida e experienciada por nós. Diante da influência com a imagem estética a pesquisa sugere um movimento de olhar para trás e recordar/reviver histórias vividas, e um olhar para frente de forma que se possa revivê-las por meio da experiência em fazer pesquisa no ensino de Química. Essa experiência se mostrou como um potencial orientador para auxiliar a constituição do professor/pesquisador. O conhecimento é essencial a toda reflexão, para Dewey (2011, p.151) "a experiência não substitui o conhecimento. A experiência é um meio para a aquisição do conhecimento".

Essas reflexões favorecem a percepção de que a produção de narrativas serve, ao mesmo tempo, como procedimento de pesquisa e como alternativa de formação. Ela permite o desvendar de elementos quase misteriosos por parte do próprio sujeito da narração que, muitas vezes, nunca havia sido estimulado a expressar organizadamente seus pensamentos. (CUNHA, 1997, p.4)

Essa experiência, vivida na disciplina, contribuiu para as discussões sobre produção de conhecimento pelas formas de pesquisar na área da Educação e, também, a importância da escrita narrativa como modo de fazer investigação a partir das experiências de cada sujeito. Basta encontrarmos modos de apresentar as narrativas, as experiências vividas, de forma que nela se perceba o não percebido. Como disse um novo olhar sobre a pesquisa e narrativa. 
O maior desafio durante as vivências como pesquisadora nesse movimento de pesquisa foi, e ainda é, encontrar uma maneira de apresentar as experiências vividas e narradas pelos participantes. Fico pensando em como seria legal compor uma escrita narrativa que apresentasse cada participante para finalizar essa experiência, mas não consigo "criar" algo assim, quem sabe um dia consiga fazer esse movimento de escrita como pesquisadora-narrativa. Aprendi com essa pesquisa que a formação de um professor/pesquisador está para além de uma simples pesquisa, a pesquisa, o modo de fazer pesquisa, a partir de experiências pessoais vividas em algum momento de nossas vidas que por alguma razão nos incomodou, nos mobilizou a querer saber.

"A pesquisa narrativa no campo de pesquisa é uma forma de viver, é um modo de vida" citam Clandinin e Connelly (2015, p. 116), e assim fiz nessa experiência, vivi o estágio docência juntamente com os caminhos da disciplina. A narrativa convida a viver em outros lugares, e assim foi esse movimento da disciplina, pois a cada narrativa, (re)vivia uma lembrança. Todos os movimentos da disciplina me permitiram refletir sobre as coisas pequenas, minúsculas, que o momento proporcionava.

\section{Considerações Finais}

No presente texto procurei compreender minha experiência como professora e pesquisadora em formação durante meu estágio de docência. Acredito que o envolvimento nos caminhos percorridos, juntamente com a turma, oportunizou a aprendizagem de trabalhar, na formação inicial de professores, com atividades que possibilitam a atuação do coletivo, e assim contribuir na compreensão sobre a pesquisa em Educação.

Destaco nas minhas narrativas a autonomia, a liberdade e alteridade em promover uma formação outra, com escuta atenta e reconhecimento da experiência de cada um como uma forma de construir conhecimento. A importância de analisar minhas narrativas se torna fundamental no processo de formação, dando significado e sentido à experiência vivida ao (re)ler cada passo dado na disciplina. Para além da formação da pesquisadora, o grupo de pesquisa formado durante a experiência do estágio se torna um coletivo em que cada indivíduo se (re)constrói através das narrativas, quando percebe que o movimento serve para transformar todos nós como sujeitos pesquisadores de nossas próprias vivências e experiências. A relação entre mim e os alunos mostra o potencial desse movimento, de Revista Interinstitucional Artes de Educar. Rio de Janeiro, V. 7, N. 1 - pág. 410-426 janeiroabril de 2021: "Pedagogias Vitais: Corpo, Desejo e Educação" DOI: 10.12957/riae.2021.54917 
partilha de vozes de todos que estão envolvidos com a experiência permitindo que cada um se/e mostre o que foi construído de conhecimento.

Como pesquisadora-narrativa percebo o quanto a escrita me (re)constrói como pessoa e que o coletivo nos faz perceber coisas para além do contar, narrar, faz com que refletimos sobre nossas próprias histórias quando contamos e (re)contamos. Esse movimento de viver a experiência com o grupo, participando e se entregando a todas as vivências, proporcionou-me autoconhecimento e um outro olhar quanto à formação inicial de professores, pois o viver a experiência me permitiu perceber o que antes não foi percebido.

Por último, percebo como a experiência de pesquisar está sendo aproveitada nos caminhos trilhados de forma aberta e atenta a todos os movimentos que esse momento proporciona. Argumento que a construção de outros olhares na pesquisa em Educação Química relacionados à narrativa, ao estético e à percepção do outro, favorecem um (re)viver, (re)cordar e (re)lembrar de vivências na formação de professores.

\section{REFERENCIAS}

BRUNER, J. A Cultura da Educação. Porto Alegre: ARTMEDE, 2001.

CALIXTO, V. S.; GALIAZZI, M. C. A constituição do professor/pesquisador no componente curricular de Monografia por meio da escrita em diários de pesquisa. Química Nova na Escola, 39(2), 170-178, 2017.

CHAVES, I.M. A Pesquisa Narrativa: Uma forma de evocar imagens da vida de professores. Educação em Debate. Fortaleza, Ano.21, v.1, n.39, p.86-93, 2000.

CLANDININ, J.; CONNELLY, M. Pesquisa Narrativa: experiência e história de pesquisa qualitativa.Tradução: Grupo de Pesquisa Narrativa e Educação de Professores ILEEL/UFU. $2^{\circ}$ edição rev. Uberlândia: Editora UFU, 2015.

CUNHA, M. I. da. Conta-me Agora! As narrativas como alternativas pedagógicas na pesquisa e no ensino. Revista da Faculdade de Educação. Vol.23, n.1-2. São Paulo. 1997.

DEWEY, J. Experiência e educação/John Dewey. Tradução de Renata Gaspar. 2. Ed. Petrópolis, RJ: Vozes, 2011.

DORNELES, A.M; GALIAZZI, M.C. Investigação Narrativa na Formação de Professores de Química. Roteiro, Joaçaba, v. 41, n. 1, p. 179-196, jan./abr. 2016.

GUEDES, A.O; RIBEIRO, T. Pesquisa, alteridade e experiência: metodologias minúsculas. Rio de Janeiro: Ayvu, 2019. 304p. 
MELLO, D. M. Histórias de subversão do currículo, conflito e resistências: buscando espaço para a formação do professor na aula de língua inglesa do curso de letras.Tese Doutorado. PUC. 2005.

MÓL, G.S. Pesquisa Qualitativa em Ensino de Química. Revista Pesquisa Qualitativa. São Paulo (SP), v.5, n.9, p. 495-513, dez. 2017.

MORAES, R. No ponto final a clareza do ponto de interrogação inicial: a construção do objeto de uma pesquisa qualitativa. Educação. Porto Alegre. Ano XXV, n.46. Março 2002.

RIBEIRO, T; SAMPAIO, C.S; SOUZA, R. Investigar Narrativamente a Formação Docente: No Encontro com o Outro, Experiências... Roteiro, Joaçaba, v.41, n.1, p.135-154, jan./abr. 2016. Disponível em: www.editora.unoesc.edu.br

SALOMON, D. V. Como fazer uma monografia. $12^{\circ}$ Edição. São Paulo: Editora WMF Martins Fontes, 2010. 425p.

SOUSA, R.S; GALIAZZI, M.C. Experiências Estéticas na Pesquisa em Educação Química: Emergências Investigativas na Formação de Professores de Química em uma Comunidade Aprendente. Revista de Educação, Ciência e Matemática. V.9. n.2. maio/agosto. 2019.

SOUZA, M.L. Histórias de professores de Química em rodas de formação em rede: Colcha de Retalhos tecida em partilhas (d)e narrativas. 1.ed. Ijuí-RS: Editora Unijuí, 2011. V.500. 248p.

\footnotetext{
i Mestranda em Educação em Ciências: Química da Vida e Saúde na Universidade Federal do Rio Grande (FURG). Graduada em Química Licenciatura pela FURG (2018). Atualmente estuda sobre pesquisa narrativa, bolsista CAPES, integrante voluntária nas oficinas de Química no Ceamecim (FURG), integrante do grupo Tramas narrativas. Tem interesse em pesquisa narrativa, formação de professores, educação, construção do conhecimento. Instituição/Afiliação: Universidade Federal do Rio Grande FURG. Rio Grande/RS - Brasil. ORCID iD https://orcid.org/0000-0003-3704-750X

ii Doutora em Educação em Ciências pela Universidade Federal do Rio Grande. Professora Adjunta da Escola de Química e Alimentos e do Programa de Pós-Graduação em Educação em Ciências: Química da Vida e Saúde da Universidade Federal do Rio Grande - FURG. Atua na área de investigação narrativa, formação de professores de Química/Ciências, ensino de Química, experimentação investigativa, dentre outras. Instituição/Afiliação: Universidade Federal do Rio Grande FURG. Rio Grande/RS - Brasil. ORCID iD https://orcid.org/0000-0001$\underline{7110-9378}$

iii Significado da palavra desobediente; que tende a desobedecer; que não é submisso; que não aceite normas, regras, etc.
} 